\title{
Measurement of Key Pool Boiling Parameters in Nanofluids for Nuclear Applications*
}

\author{
In Cheol BANG**, Jacopo BUONGIORNO**, Lin-Wen HU** and Hsin WANG*** \\ ${ }^{* *}$ Massachusetts Institute of Technology \\ 77 Massachusetts Ave., Cambridge, MA 02139, USA \\ E-mail: jacopo@mit.edu \\ ***Oak Ridge National Laboratory \\ Oak Ridge, TN 37831, USA
}

\begin{abstract}
Nanofluids, colloidal dispersions of nanoparticles in a base fluid such as water, can afford very significant Critical Heat Flux (CHF) enhancement. Such engineered fluids potentially could be employed in reactors as advanced coolants in safety systems with significant safety and economic advantages. However, a satisfactory explanation of the CHF enhancement mechanism in nanofluids is lacking. To close this gap, we have identified the important boiling parameters to be measured. These are the properties (e.g., density, viscosity, thermal conductivity, specific heat, vaporization enthalpy, surface tension), hydrodynamic parameters (i.e., bubble size, bubble velocity, departure frequency, hot/dry spot dynamics) and surface conditions (i.e., contact angle, nucleation site density). We have also deployed a pool boiling facility in which many such parameters can be measured. The facility is equipped with a thin indium-tin-oxide heater deposited over a sapphire substrate. An infra-red high-speed camera and an optical probe are used to measure the temperature distribution on the heater and the hydrodynamics above the heater, respectively. The first data generated with this facility already provide some clue on the CHF enhancement mechanism in nanofluids. Specifically, the progression to burnout in a pure fluid (ethanol in this case) is characterized by a smoothly-shaped and steadily-expanding hot spot. By contrast, in the ethanol-based nanofluid the hot spot pulsates and the progression to burnout lasts longer, although the nanofluid CHF is higher than the pure fluid CHF. The presence of a nanoparticle deposition layer on the heater surface seems to enhance wettability and aid hot spot dissipation, thus delaying burnout.
\end{abstract}

Key words: Nanofluids, Pool Boiling, Critical Heat Flux

\section{Introduction}

One of the most intriguing features of nanofluids, which are engineered colloidal suspensions of nanoparticles, is their ability to enhance the Critical Heat Flux (CHF) significantly. A summary of the nanofluid CHF studies reported to date is reported in Table 1. Note that large effects on CHF (up to $+200 \%$ ) are obtained at relatively low nanoparticle concentrations, as low as $0.001 \%$ vol. At MIT we are exploring the possibility to exploit the unique heat removal characteristics of nanofluids to improve the safety and/or economics of nuclear systems ${ }^{(1)}$. However, a persuasive explanation of the CHF enhancement mechanism in nanofluids is yet to be found. This paper will identify the key boiling parameters needed to close this gap $(\S 2)$, and describe a pool boiling facility to 
measure them (§3). Finally, some preliminary data generated in said facility will be presented $(\S 4)$.

Table I. CHF enhancement in nanofluids.

\begin{tabular}{|c|c|c|c|}
\hline Ref & Nanofluid(s) & Heater type & $\begin{array}{c}\text { Max CHF } \\
\text { enhancement }\end{array}$ \\
\hline$(2)$ & $\mathrm{Al}_{2} \mathrm{O}_{3}$ in water, $0.001-0.025 \mathrm{~g} / \mathrm{L}$ & Cu plate & $200 \%$ \\
\hline$(3)$ & $\mathrm{SiO}_{2}(15-50 \mathrm{~nm})$ in water, $0.5 \mathrm{v} \%$ & NiCr wire & $60 \%$ \\
\hline$(4)$ & $\mathrm{Al}_{2} \mathrm{O}_{3}(38 \mathrm{~nm})$ in water, $0.037 \mathrm{~g} / \mathrm{L}$ & Ti layer on glass & $67 \%$ \\
\hline$(5)$ & $\mathrm{TiO}_{2}(27-85 \mathrm{~nm})$ in water, $0.01-3 \mathrm{v} \%$ & Cu plate & $50 \%$ \\
\hline (6) & $\begin{array}{l}\mathrm{Al}_{2} \mathrm{O}_{3}(70-260 \mathrm{~nm}) \text { and } \mathrm{ZnO} \text { in water } \\
\mathrm{Al}_{2} \mathrm{O}_{3} \text { in ethylene glycol }\end{array}$ & Cu plate & $200 \%$ \\
\hline$(7)$ & $\mathrm{Al}_{2} \mathrm{O}_{3}(10-100 \mathrm{~nm})$ in water, $0.5-4 \mathrm{v} \%$ & Stainless steel & $50 \%$ \\
\hline$(8)$ & $\mathrm{TiO}_{2}(85 \mathrm{~nm})$ in water, $10^{-5}-10^{-1} \mathrm{v} \%$ & NiCr wire & $200 \%$ \\
\hline$(9)$ & $\mathrm{SiO}_{2}, \mathrm{CeO}_{2}, \mathrm{Al}_{2} \mathrm{O}_{3}(10-20 \mathrm{~nm})$ in water, $0.5 \mathrm{v} \%$ & NiCr wire & $170 \%$ \\
\hline (10) & $\mathrm{Au}(4 \mathrm{~nm})$ in water & $\mathrm{Cu}$ plate & $175 \%$ \\
\hline$(11)$ & $\begin{array}{l}\mathrm{SiO}_{2}(20-40 \mathrm{~nm}), \mathrm{ZrO}_{2}(110-250 \mathrm{~nm}), \mathrm{Al}_{2} \mathrm{O}_{3} \\
(110-210 \mathrm{~nm}) \text { in water, } 0.001-0.1 \mathrm{v} \%\end{array}$ & $\begin{array}{l}\text { Stainless steel } \\
\text { wire }\end{array}$ & $80 \%$ \\
\hline
\end{tabular}

\section{Nomenclature}

c Specific heat, $\mathrm{J} / \mathrm{kg} \cdot \mathrm{K}$

$d_{c} \quad$ Critical diameter, $\mathrm{m}$

$D \quad$ Diameter, $\mathrm{m}$

$f$ Frequency, $\mathrm{Hz}$

$g$ Gravity acceleration, $\mathrm{m} / \mathrm{s}^{2}$

$h \quad$ Specific enthalpy, $\mathrm{J} / \mathrm{kg}$

$k$ Thermal conductivity, $\mathrm{W} / \mathrm{m} \cdot \mathrm{K}$

$N_{A} \quad$ Nucleation site density, $\mathrm{m}^{-2}$

$q^{\prime \prime} \quad$ Heat flux, $\mathrm{W} / \mathrm{m}^{2}$

$r \quad$ Roughness factor

$T$ Temperature, ${ }^{\circ} \mathrm{C}$

Greek Letters

$\alpha \quad$ Void fraction

$\delta_{e} \quad$ Macrolayer thickness, $\mathrm{m}$

$\gamma$ Surface energy, $\mathrm{N} / \mathrm{m}$

$\varphi$ Nanoparticle volumetric fraction

$\theta$ Contact angle, degree

$\rho \quad$ Density, $\mathrm{kg} / \mathrm{m}^{3}$

$\sigma$ Surface tension, $\mathrm{N} / \mathrm{m}$

$\tau$ Time, $\mathrm{s}$

\section{Subscripts}
$b \quad$ Bubble
c Cavity
CHF Critical heat flux
$f \quad$ Liquid phase
$f g$ Liquid-to-vapor transition
$g \quad$ Vapor phase
$h$ Heater material 


$\begin{array}{ll}m & \text { Mushroom bubble } \\ p & \text { Nanoparticle } \\ s & \text { Surface } \\ \text { sat } & \text { Saturation } \\ \text { SL } & \text { Solid-Liquid } \\ \text { SV } & \text { Solid-Vapor }\end{array}$

2. Parameters Needed for a Comprehensive Investigation of Nanofluids Pool Boiling and Critical Heat Flux

\subsection{Nucleate Boiling Parameters}

At relatively low heat fluxes, nucleate-boiling heat transfer is dominated by the intense agitation and transient conduction within the liquid phase near the surface, as the bubbles grow and depart from the surface. However, at intermediate to high heat fluxes, close to $\mathrm{CHF}$, the latent heat of the bubbles becomes the prevalent heat removal mechanism, so the heat flux, $q^{\prime \prime}$, can be written as follows:

$$
q^{\prime \prime}=\frac{\pi D_{b}^{3}}{6} \rho_{g} h_{f g} f_{b} N_{A}
$$

This equation suggests that the bubble departure diameter $\left(D_{b}\right)$, the departure frequency $\left(f_{b}\right)$ and the nucleation site density $\left(N_{A}\right)$ are important parameters to describe nucleate boiling. Numerous models and correlations have been proposed in the past for these parameters. For example:

$$
\begin{aligned}
& D_{b}=0.0208 \theta\left[\frac{\sigma}{g\left(\rho_{f}-\rho_{g}\right)}\right]^{1 / 2} \operatorname{Ref.~(12)~} \\
& f_{b} D_{b}=0.59\left[\frac{\sigma g\left(\rho_{f}-\rho_{g}\right)}{\rho_{f}^{2}}\right]^{1 / 4} \operatorname{Ref.~(13)~} \\
& N_{A}=5 \times 10^{-27}(1-\cos \theta) / d_{c}^{6}, d_{c}=\frac{4 \sigma T_{s a t}}{\rho_{g} h_{f g} \Delta T_{s}} \quad \text { Ref. (14) }
\end{aligned}
$$

where in addition to the thermo-physical and thermodynamic properties, the contact angle ( $\theta$ ) and the surface superheat $\left(\Delta T_{s}\right)$ also appear. The contact angle, which is a measure of the wettability of the surface, deserves particular attention in the case of nanofluids boiling for the following reason. For a generic rough surface the contact angle can be found from the modified Young's equation:

$$
\cos \theta=r \frac{\gamma_{S V}-\gamma_{S L}}{\sigma} \quad \text { Ref. (15) }
$$

where $r$ is a roughness factor, defined as the ratio of the effective (rough) contact area to the smooth contact area, and $\gamma_{S V}-\gamma_{S L}$ is the so-called adhesion tension of the surface materials. In a previous paper ${ }^{(16)}$ it was shown that a porous layer of nanoparticles deposits on the heater surface upon nucleate boiling. This layer changes the surface chemical composition, morphology and roughness, and thus the contact angle as well. Indeed it was shown that 
wettability is greatly affected by the presence of a nanoparticle layer on the surface ${ }^{(16)}$.

\subsection{CHF Parameters}

Despite several decades of intense study a consensus explanation of the physical mechanism causing CHF is yet to be found, even for the simple situation of a pure fluid, let alone nanofluids. Most hypotheses fall into one of the following four categories:

A) Hydrodynamic instability theory, which postulates that CHF occurs when the downflow of fresh liquid to the heated surface is prevented by the rising vapor ${ }^{(17)(18)}$. The CHF is calculated as:

$$
q_{C H F}^{\prime \prime}=C \cdot h_{f g} \rho_{g}^{1 / 2} \sigma^{1 / 4} g^{1 / 4}\left(\rho_{f}-\rho_{g}\right)^{1 / 4}
$$

where $C$ is an empirical constant depending on the geometry of the heater. The hydrodynamic instability theory notably excludes any effect of the heated surface characteristics (i.e., roughness, wettability, etc.) on CHF, and for this reason has come under well-substantiated criticism in recent years (see for example Ref. (19)).

B) Macrolayer dryout theory, which assumes CHF is the result of dryout of a liquid macrolayer under large mushroom-shaped bubbles hovering above the heated surface for a relatively long time before departing ${ }^{(20)}$. CHF is calculated as:

$$
q_{C H F}^{\prime \prime}=\rho_{f} h_{f g} \delta_{e}(1-\alpha) f_{m}
$$

where $\alpha$ is the void fraction at the surface, $f_{m}$ is the departure frequency of the mushroom bubble, and an expression for the macrolayer thickness $\left(\delta_{e}\right)$ has been proposed by Sadisivian et al. ${ }^{(21)}$ :

$$
\delta_{e}=0.5\left(N_{A}\right)^{-0.5}\left[\cos \theta-\frac{\pi}{12}\left(3 \cos \theta-\cos ^{3} \theta\right)\right]
$$

which shows the importance of the contact angle.

C) Hot/dry spot theory, which assumes CHF occurs due to an irreversible temperature excursion within localized hot/dry spots the surface ${ }^{(19)}$. Theofanous and Dinh ${ }^{(22)}$, considered the microhydrodynamics of the solid-liquid-vapor line at the boundary of a hot/dry spot and calculated the CHF as:

$$
q_{C H F}^{\prime \prime}=k^{-1 / 2} h_{f g} \rho_{g}^{1 / 2} \sigma^{1 / 4} g^{1 / 4}\left(\rho_{f}-\rho_{g}\right)^{1 / 4}
$$

Interestingly, this equation and the hydrodynamic theory equation are essentially the same, except for the parameter k, which according to Theofanous and Dinh ${ }^{(22)}$ "for a well-wetting surface is smaller than for a poorly-wetting surface", i.e., everything else being the same, a well-wetting surface will have a higher CHF than a poorly-wetting surface.

D) Bubble interaction theory, which postulates CHF occurs when at high heat flux the bubble number and departure frequency become so high that the bubbles coalesce radially, 
thus preventing liquid access to the surface ${ }^{(23)}$. Another interesting model was suggested by Kolev ${ }^{(24)}$ who considered the shear force generated by the mutual interaction of the growing and departing bubbles, and the effect such shear force has on nucleate boiling near CHF. According to Kolev's model ${ }^{(24)}$ the nucleate-boiling heat flux near CHF can be expressed as follows:

$$
q^{\prime \prime} \propto N_{A}^{1 / 4} \Delta T_{s}^{2}\left(1+0.3 \frac{\Delta \tau_{w}}{\Delta \tau_{d}}\right)^{-1 / 2}
$$

which emphasizes the role of the bubble wait time $\left(\Delta \tau_{w}\right)$ and departure time $\left(\Delta \tau_{d}\right)$, but also the role of the surface conditions, including the contact angle, via the nucleation site density.

In summary, a review of the nucleate boiling and CHF state-of-the-art clearly suggests that a credible attempt at explaining the mechanism(s) responsible for the large CHF enhancement observed in nanofluids must include accurate knowledge of the following parameters:

- Properties

-Liquid density, viscosity, thermal conductivity and specific heat

-Vapor density

-Enthalpy of vaporization

-Surface tension

- Hydrodynamics

-Bubble size

-Bubble velocity

-Departure frequency (or hovering time)

- Liquid macrolayer thickness

-Hot/dry spot dynamics (meniscus behavior)

- Surface conditions

- Contact angle (wettability)

- Nucleation site density

Unfortunately, some studies in the literature use poorly-characterized nanofluids with little information about thermophysical properties or even nanoparticle loading and size. Most studies lack the diagnostics necessary for measuring the nucleation site density. Characterization of the near-surface hydrodynamics is typically ignored. The contact angle for nanofluids is rarely measured and wetting effects in general are overlooked. Our research program aims at closing these gaps. The important thermo-physical and thermodynamic properties of nanofluids are routinely measured/estimated in our lab, and typically found to change imperceptibly from those of the base fluid because of the low nanoparticle concentrations used in our tests $(<0.1 \%$ vol. $)$. The salient characteristics of a facility for measuring the other important boiling and CHF parameters are described next.

\section{Description of the MIT Nanofluid Pool Boiling Facility}

A schematic and drawing of the facility are shown in Fig. 1. Boiling occurs on a flat plate consisting of a $24 \times 10 \mathrm{~mm}^{2}, 0.7 \mu \mathrm{m}$ thick Indium-Tin-Oxide (ITO) heater, vacuum deposited on a $1 \mathrm{~mm}$ thick sapphire substrate, purchased from Diamond Coatings Ltd. The ITO heater is connected to a power supply, to control the heat flux at the surface. 
Heat fluxes as high as $6 \mathrm{MW} / \mathrm{m}^{2}$ are possible with this configuration, well over the expected CHF for nanofluids. The cell accommodating the test fluid is sealed, includes a condenser and is surrounded by a constant-temperature water bath, to minimize heat losses to the ambient. Several thermocouples within the test cell monitor the bulk temperature of the test fluid. The cell can operate at pressures in the 2 to $200 \mathrm{kPa}$ range, however we plan to run our experiments mostly at atmospheric pressure. To acquire the temperature distribution on the heater surface, an Infra Red (IR) camera measures, via a gold-coated mirror, the IR intensity through the sapphire substrate, which is transparent to light in the IR region. The IR intensity is converted to temperature through calibration. The thinness of the ITO heater guarantees that the IR camera reading from the bottom is an accurate representation of the actual temperature on the top (wet side) of the heater surface. The surface roughness of the as-purchased ITO glass heater was measured using an atomic force microscope (AFM), and found to be of the order of $20 \mathrm{~nm}$.

Use of the IR camera (vs. the more traditional approach based on thermocouples embedded at discrete positions in the heater) enables mapping of the complete two-dimensional time-dependent temperature distribution on the heater surface. The camera has a space and time resolution of $100 \mu \mathrm{m}$ and $1 \mathrm{kHz}$, respectively, which is sufficient to capture the temperature history of individual bubble nucleation events at the nucleation sites. The two-phase flow hydrodynamics above the heater surface, including important parameters such as void fraction, liquid macrolayer thickness, bubble diameter and bubble velocity, are examined with a double-tip optical probe equipped with a precision positioning system that can position the probe tip within $10 \mu \mathrm{m}$ of the heater surface.

The pool boiling facility is used in a "power-controlled" mode, which entails a step-wise escalation to CHF. At each intermediate step all important parameters are recorded. The cell has been designed for easy washing and rinsing to remove residual nanoparticles on the walls. As part of the heater "post-mortem" examination, the static contact angle can be measured to assess the change in surface wettability upon precipitation of the nanoparticles.
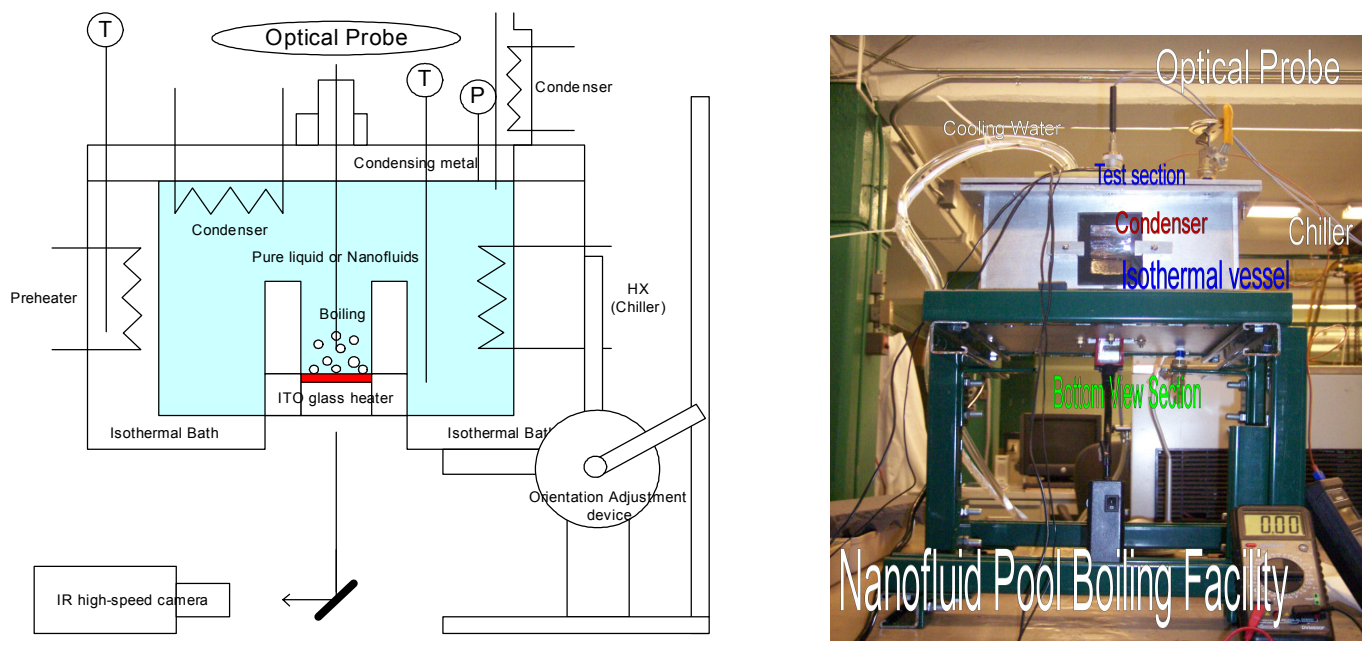

Fig. 1. MIT nanofluid pool boiling facility

\section{Preliminary Test Results and Discussion}

The first series of tests was conducted with an ethanol-based nanofluid with $0.01 \%$ vol. alumina $\left(\mathrm{Al}_{2} \mathrm{O}_{3}\right)$ nanoparticles and no surfactants. The choice of ethanol vs. water for these preliminary tests was simply driven by the convenience of using a fluid with lower boiling point and CHF. The nanoparticle size distribution was acquired with a dynamic-light-scattering analyzer, indicating an average alumina particle diameter of 118.2 
nm.

Boiling tests for pure ethanol and the nanofluid were run and the results compared. The nanofluid exhibited a modest (but not negligible) CHF enhancement, i.e., $\sim 530 \mathrm{~kW} / \mathrm{m}^{2}$ vs. $\sim 480 \mathrm{~kW} / \mathrm{m}^{2}$ for pure ethanol. Figures 2 and 3 show series of temperature maps for the whole heater at the onset of $\mathrm{CHF}$, for pure ethanol and the nanofluid, respectively. In these images temperature is represented by the color spectrum ranging from blue (cold) to red (hot). In both cases the CHF progression is characterized by an expanding hot spot. However, there are four remarkable differences in the behavior of the nanofluid. First, the presence of several non-expanding hot spots far from the main hot spot. Second, the presence of many cold spots. Third, the endurance of cold patches within and around the expanding hot spot (see, for example, frames 1, 4, 8 and 12 in Fig. 3). Fourth, the semi-cyclic nature of the hot spot expansion, i.e., the hot spot undergoes two cycles (frames 1-4 and 4-8) in which it first seems to decisively expand, but then retreats to the initial conditions (frames 1, 4 and 8 are virtually indiscernible), before the irreversible runaway occurs (frames 9-15). By contrast, the hot spot in the pure ethanol test seems to expand much more regularly and with a smooth elliptical boundary (Fig. 2).
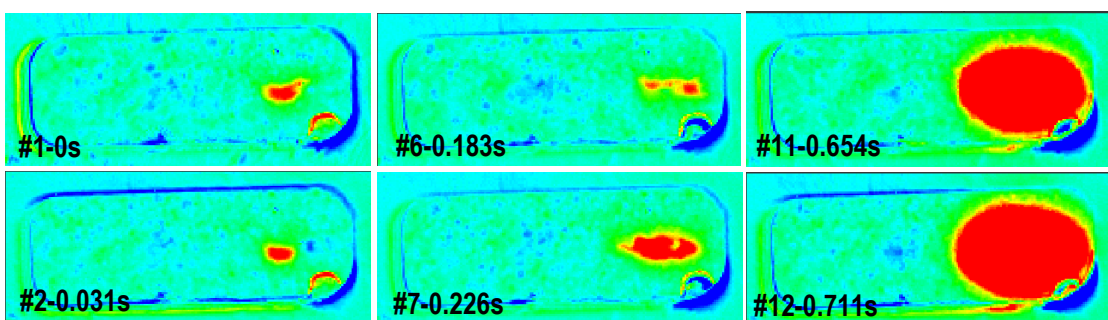

IR Intensity

8757
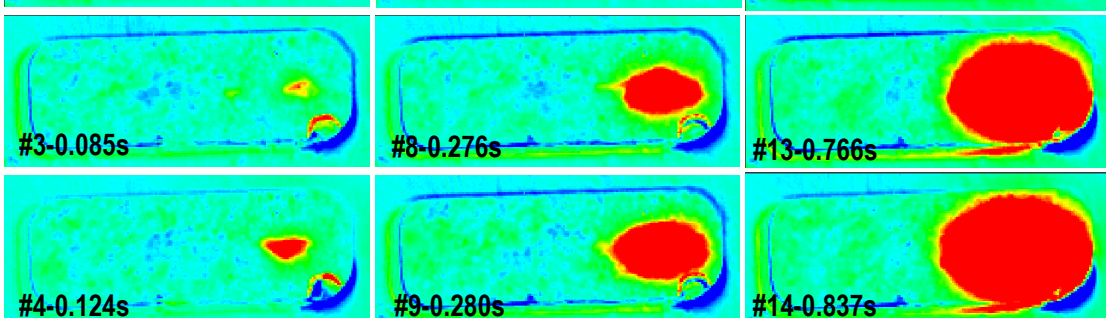

7500
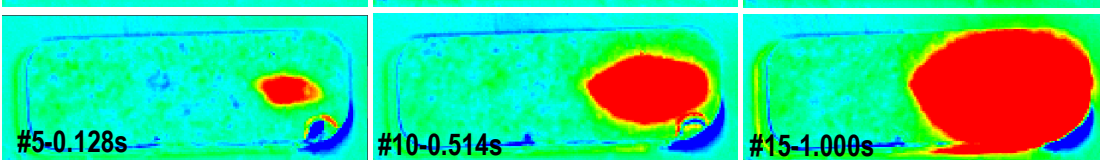

7267

107.7

Fig. 2. IR images of CHF in pure ethanol $\left(\sim 480 \mathrm{~kW} / \mathrm{m}^{2}\right)$ 

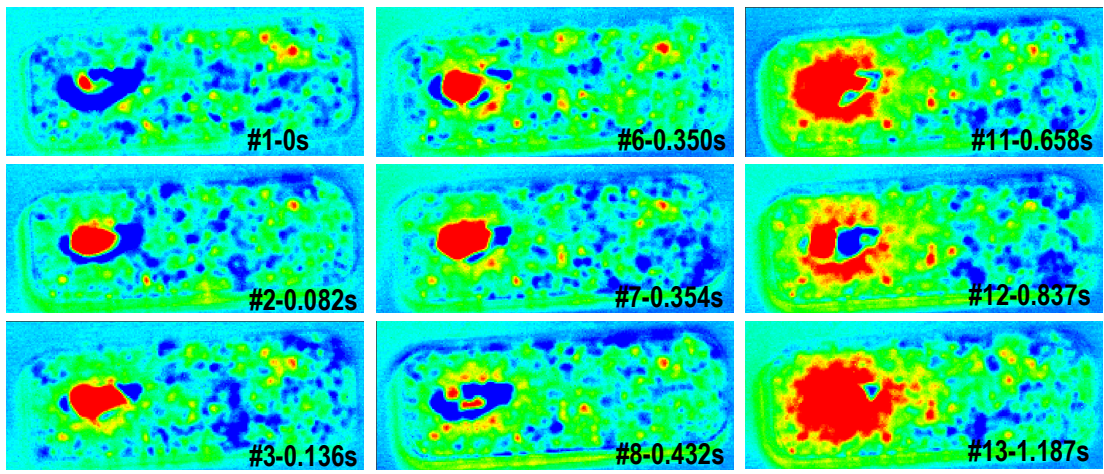

IR Intensity $\quad \quad{ }^{\circ} \mathrm{C}$

$8757 \square 147.6$
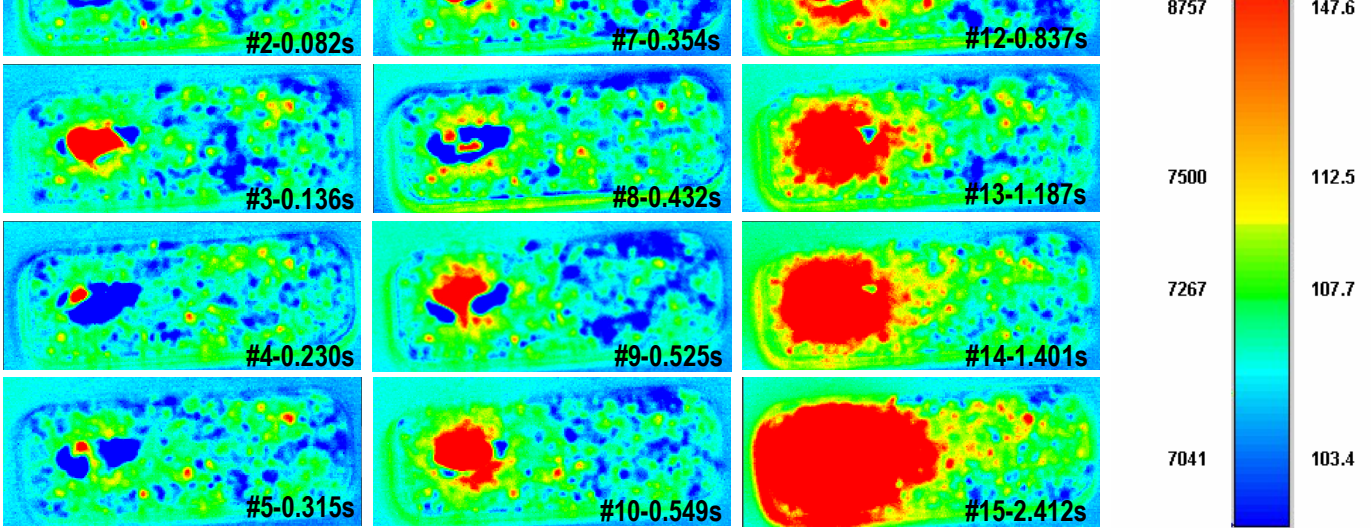

Fig. 3. IR images of CHF in ethanol-based alumina nanofluid $\left(\sim 530 \mathrm{~kW} / \mathrm{m}^{2}\right)$

Figure 4 shows that significant deposition of alumina nanoparticles took place on the ITO heater surface during the nanofluid test, as expected, while the surface remained clean during the pure ethanol test. The key to explaining the aforementioned differences in CHF behavior is likely to lie in this nanoparticle deposition layer.

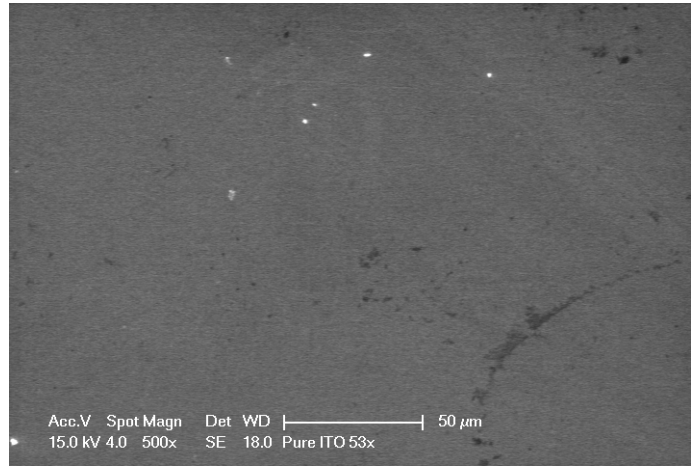

(a)

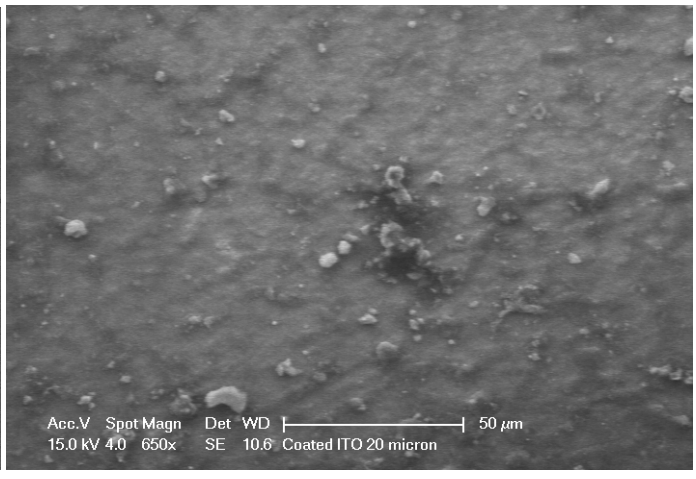

(b)

Fig. 4. SEM images of (a) clean ITO surface and (b) ITO surface boiled in nanofluid

The layer seems to have reduced the contact angle on the heater surface to nearly perfect spreading, though the wettability of ITO by ethanol is very high to begin with (Fig. 5). Because of the modest improvement of wettability in this case, some other mechanism may be more important in aiding CHF enhancement. For example, the nanoparticle layer may alter the number of nucleation sites, as suggested by the differences in the boiling curves (Fig. 6) and IR images at different heat fluxes (Fig. 7), and/or assist in dissipating the hot spot by enhancing radial conduction on the surface. The latter effect is typically described by the so-called 'thermal activity', $S$ :

$$
S=\delta \sqrt{\rho_{h} c_{h} k_{h}}
$$

which is the product of the heater characteristic dimension $(\delta)$ and the heater material 
effusivity $\left(\sqrt{\rho_{h} c_{h} k_{h}}\right)$. The thermal properties of the materials of interest are reported in

Table 2. The higher the thermal activity, the more effectively conduction can dissipate the hot/dry spot. According to Arik and Bar-Cohen ${ }^{(25)}$ the effect 'saturates' for $S>8$ $\mathrm{J} /\left(\mathrm{m} \cdot \mathrm{K} \cdot \mathrm{s}^{1 / 2}\right)$. The value of the thermal activity for our ITO heater is about 0.003 $\mathrm{J} /\left(\mathrm{m} \cdot \mathrm{K} \cdot \mathrm{s}^{1 / 2}\right)$, suggesting that rewetting may be conduction limited. The nanoparticle layer, whose thickness is of the order of a few microns, can add up to $0.1 \mathrm{~J} /\left(\mathrm{m} \cdot \mathrm{K} \cdot \mathrm{s}^{1 / 2}\right)$, which is not a negligible effect. A more quantitative processing of the IR data about the hot spot will help to sort out the relative importance of these effects in determining the CHF differences observed for nanofluids.

Finally, while the nanoparticle-induced improvement of surface wettability is beneficial to $\mathrm{CHF}$, it may reduce the nucleate boiling heat transfer coefficient (as indicated by a shift of the boiling curve to the right in Fig. 6). If nanofluids are to be used in practical applications, this effect must be minimized (e.g., through an increase in the number of microcavities), to ensure that the operating wall temperatures are not unacceptably high.

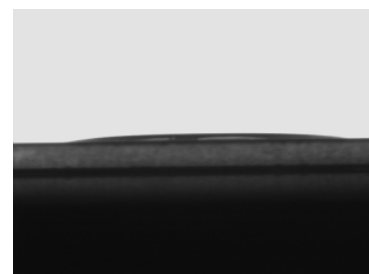

(a) $\theta \sim 5.3^{\circ}$

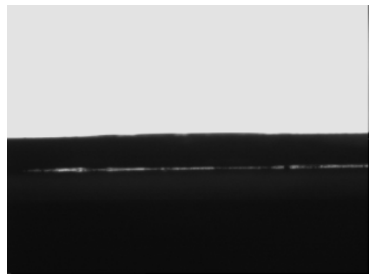

(c) $\theta \sim 1.4^{\circ}$

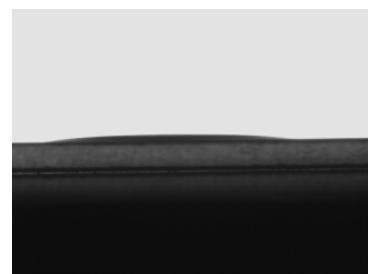

(b) $\theta \sim 5.6^{\circ}$

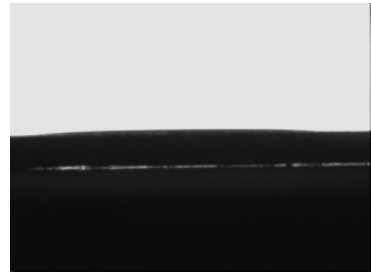

(d) $\theta \sim 2.5^{\circ}$

Fig. 5. Contact angles of sessile droplets, measured with a Krüss goniometer equipped with a camera monitor. (a) Pure ethanol on clean ITO surface, (b) Nanofluid droplet on clean ITO surface, (c) Pure ethanol on ITO surface boiled in nanofluid, (d) Nanofluid droplet on ITO surface boiled in nanofluid. 


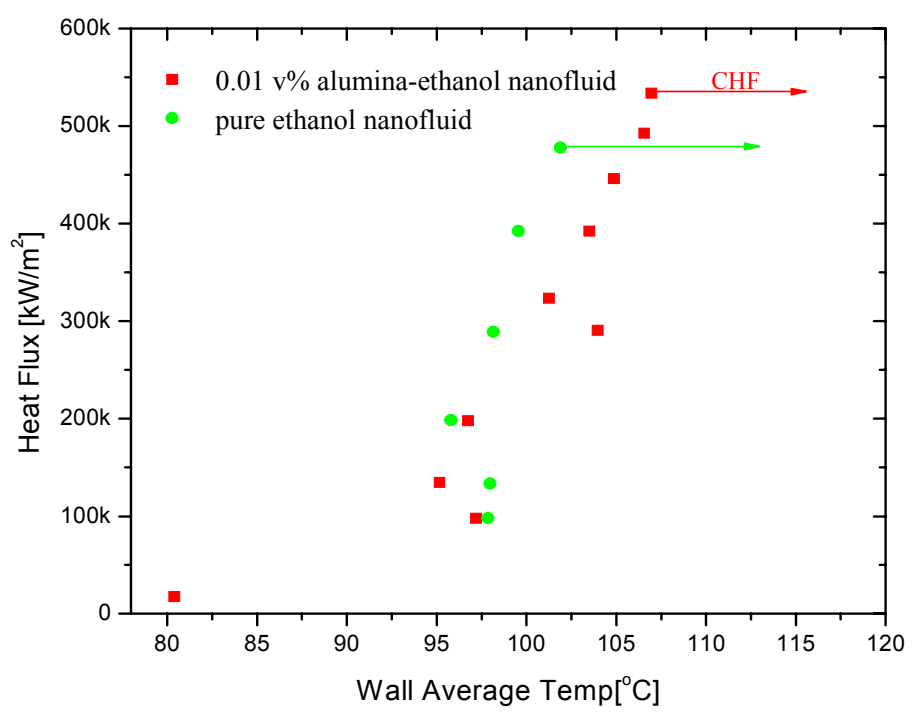

Fig. 6. Boiling curves of pure ethanol and alumina ethanol nanofluid (the boiling point of ethanol is $78^{\circ} \mathrm{C}$ )

$98 \mathrm{~kW} / \mathrm{m}^{2}$
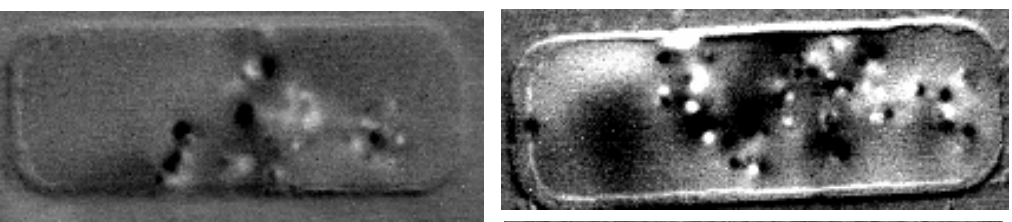

$133 \mathrm{~kW} / \mathrm{m}^{2}$
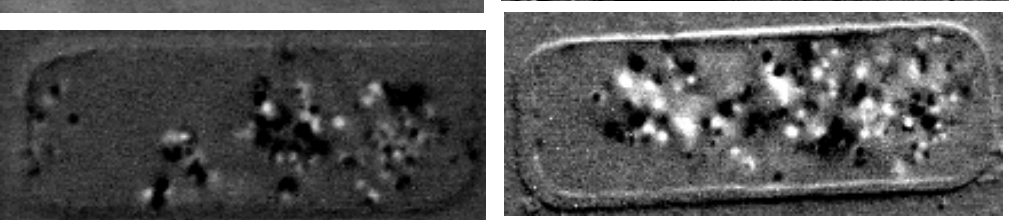

$198 \mathrm{~kW} / \mathrm{m}^{2}$
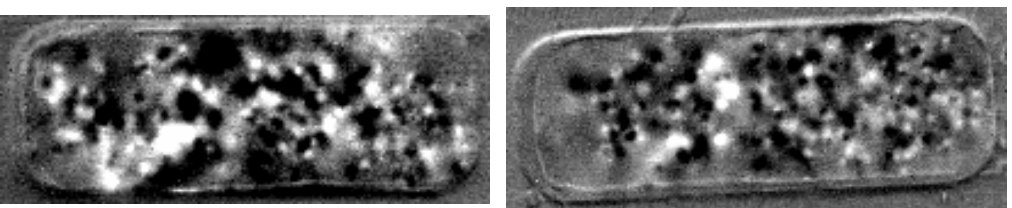

$289 \mathrm{~kW} / \mathrm{m}^{2}$
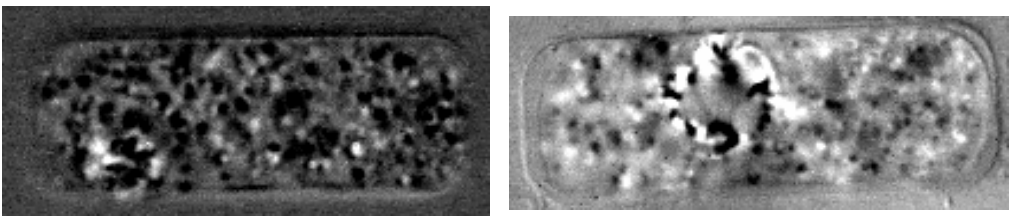

$382 \mathrm{~kW} / \mathrm{m}^{2}$

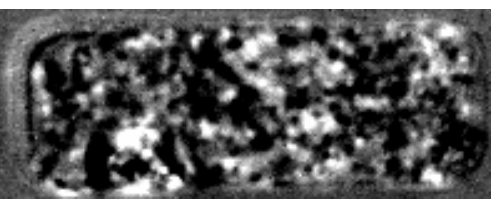

(a)

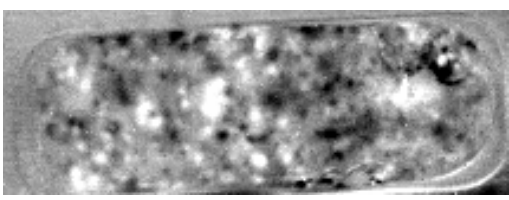

(b)

Fig. 7. IR images of the ITO surface at different heat fluxes for pure ethanol (a) and nanofluid boiling (b). 
Table 2. Thermal properties of ITO and alumina

\begin{tabular}{|c|c|c|c|c|c|}
\hline & $\rho_{h}$ & $c_{h}$ & $k_{h}$ & $\sqrt{\rho_{h} c_{h} k_{h}}$ & $S$ \\
& $\left(\mathrm{~kg} / \mathrm{m}^{3}\right)$ & $\mathrm{J} / \mathrm{kg} \cdot \mathrm{K})$ & $(\mathrm{W} /(\mathrm{m} \cdot \mathrm{K}))$ & $\left(\mathrm{J} /\left(\mathrm{m}^{2} \cdot \mathrm{K} \cdot \mathrm{s}^{1 / 2}\right)\right)$ & $\mathrm{J} /\left(\mathrm{m} \cdot \mathrm{K} \cdot \mathrm{s}^{1 / 2}\right)$ \\
\hline $\mathrm{ITO}$ & 7160 & 340 & 8.7 & $\sim 4602$ & $\sim 0.003$ \\
\hline $\mathrm{Al}_{2} \mathrm{O}_{3}$ & 4000 & 760 & $\sim 40$ & $\sim 11,100$ & $\sim 0.1$ \\
\hline
\end{tabular}

\section{Conclusions}

To reach a defensible explanation of the mechanism of CHF enhancement in nanofluids, it is necessary to know the fluid properties, hydrodynamic parameters such as the macrolayer thickness, and, importantly, surface parameters such as the nucleation site density and the contact angle. We have deployed a boiling facility where such parameters can be rigorously measured. The data from some preliminary tests with an ethanol-based alumina particle nanofluid suggest that the presence of a nanoparticle layer on the surface may be responsible for the observed CHF enhancement via increase of the surface wettability and/or dissipation of the hot spot by radial conduction. Furthermore, the unique characteristics of the hot spot dynamics in nanofluids at CHF was studied directly with IR thermometry and presented for the first time in this paper. A systematic investigation of boiling and CHF in nanofluids is currently underway in our labs including measurement of key hydrodynamic parameters by means of a double-tip optical probe.

\section{Acknowledgements}

The authors thank Mr. Peter Stahle and Dr. Thomas McKrell for their help in constructing the pool boiling facility, and Mr. Brad Cicciarelli for the contact angle measurements. The nanofluid program at MIT is sponsored by AREVA, the Idaho National Laboratory, the Nuclear Regulatory Commission, and the DOE Innovation in Nuclear Infrastructure and Education Program. The Korea Research Foundation is gratefully acknowledged for Dr. Bang's post-doctoral fellowship. The authors are also thankful to the Oak Ridge National Lab HTML user program, which provided the IR camera, and to the Center for Nanoscale Systems (CNS) at Harvard University for granting the use of their AFM facility.

\section{References}

(1) Buongiorno J. and L.-W. Hu, Nanofluid Coolants for Advanced Nuclear Power Plants, Paper 5705, Proceedings of ICAPP '05, Seoul, May 15-19 (2005).

(2) You S. M., J. Kim, K. H. Kim, Effect of nanoparticles on critical heat flux of water in pool boiling heat transfer, Applied Physics Letters, Vol. 83, No. 16, (2003), pp. 3374-3376.

(3) Vassallo P., R. Kumar, S. D'Amico, Pool boiling heat transfer experiments in silica-water nano-fluids, Int. J. of Heat and Mass Transfer, Vol. 47, (2004), pp. 407-411.

(4) Tu J. P., N. Dinh, T. Theofanous, An experimental study of nanofluid boiling heat transfer, in Proceedings of $6^{\text {th }}$ International Symposium on Heat Transfer, Beijing, China, (2004).

(5) Kim H. D. and M. H. Kim, Critical heat flux behavior in pool boiling of water- $\mathrm{TiO}_{2}$ nano-fluids, Proceedings of Fourth Japan-Korea Symposium on Nuclear Thermal Hydraulics and Safety, Sapporo, Japan, November 28-December 1, (2004). 
(6) Moreno G. Jr., S. Oldenburg, S. M. You, J. H. Kim, Pool Boiling Heat Transfer of Alumina-Water, Zinc Oxide-Water and Alumina-Water Ethylene Glycol Nanofluids, Proceedings of HT2005, July 17-22, San Francisco, California, USA, (2005).

(7) Bang I. C. and S. H. Chang, Boiling Heat Transfer Performance and Phenomena of $\mathrm{Al}_{2} \mathrm{O}_{3}$-Water Nano-fluids from a Plain Surface in a Pool, Int. J. of Heat and Mass Transfer, Vol. 48, (2005), pp. 2407-2419.

(8) Kim H., J. Kim, M. Kim, Experimental study on CHF characteristics of water- $\mathrm{TiO}_{2}$ nano-fluids, Nuclear Engineering and Technology, Vol. 38, No. 1, (2006).

(9) Milanova D., R. Kumar, S. Kuchibhatla, S. Seal, Heat transfer behavior of oxide nanoparticles in pool boiling experiment, Proc. of $4^{\text {th }}$ International Conference on Nanochannels, Microchannels and Minichannels, Limerick, Ireland, June 19-21, (2006).

(10) Jackson J. E., B. V. Borgmeyer, C. A. Wilson, P. Cheng, J. E. Bryan, Characteristics of nucleate boiling with gold nanoparticles in water, Proceedings of IMECE 2006, Chicago, November 5-10, (2006).

(11) Kim S. J., I. C. Bang, J. Buongiorno, L. W. Hu, Surface Wettability Change during Pool Boiling of Nanofluids and its effect on Critical Heat Flux, Int. J. Heat Mass Transfer, Vol. 50, (2007), pp. 4105-4116.

(12) Fritz W., Berechnung des Maximal Volume von Dampfblasen, Phys. Z., Vol. 36, (1935), pp. 379.

(13) Zuber N., Nucleate boiling - the region of isolated bubbles - similarity with natural convection, Int. J. Heat Mass Transfer, Vol. 6, 53, (1963).

(14) Wang C. H. and V. K. Dhir, Effect of surface wettability on active nucleation site density during pool boiling of water on a vertical surface, J. Heat Transfer, Vol. 115, (2003), pp. 659-669.

(15) Wenzel R. N., Surface roughness and contact angle (letter), J. Physical Colloid Chemistry, Vol. 53, No. 9, (1949), p. 1466.

(16) Kim S. J., Bang I. C., Buongiorno, J., Hu, L.W., Effects of nanoparticle deposition on surface wettability influencing boiling heat transfer in nanofluids, Applied Physics Letters, Vol. 89, (2006), pp. 153107.

(17) Kutateladze S. S., and A. I. Leont'ev, Turbulent boundary layers in compressible gases, D. B. Spalding, Trans., Academic Press, New York (1964).

(18) Zuber N., Hydrodynamic Aspects of Boiling Heat Transfer, AECU-4439, (1959).

(19) Theofanous T. G., J. P. Tu, A. T. Dinh, T. N. Dinh, The boiling crisis phenomenon. Part II: dryout dynamics and burnout, Experimental Thermal and Fluid Science, Vol. 26, (2002), pp. 793-810.

(20) Haramura Y. and Y. Katto, A new hydrodynamic model of CHF applicable widely to both pool and forced convection boiling on submerged bodies in saturated liquids, Int. J. of Heat and Mass Transfer, Vol. 26, (1983), pp. 389-399.

(21) Sadasivan P., P. R. Chappidi, C. Unal, and R. A. Nelson, Possible Mechanisms of Macrolayer Formation, Pool and External Flow Boiling (ASME 1992), (1992), p. 135.

(22) Theofanous T. G. and T. N. Dinh, High heat flux boiling and burnout as microphysical phenomena: mounting evidence and opportunities, Multiphase Science and Technology, Vol. 18, No. 1, (2006), pp. 1-26.

(23) Rosenhow W. and P. Griffith, Correlation of Maximum Heat Flux Data for Boiling of Saturated Liquids, Chem. Eng. Prog. Symp. Ser. 52, Vol. 18, (1956), pp. 47-49.

(24) Kolev N., How accurately can we predict nucleate boiling?, in Multiphase Flow Dynamics 2, Springer (2002).

(25) Arik M. and A. Bar-Cohen, Effusivity-based correlation of surface property effects in pool boiling CHF of dielectric liquids, Int. J. Heat Mass Transfer, Vol. 46, (2003), pp. 3755-3764. 